\title{
Sacral herpes zoster presenting as sciatica
}

\section{Min-Hsiang Hung MD, Jinn-Rung Kuo MD, Kuo-Feng Huang MD, Wen-Ching Wang MD}

Previously published at www.cmaj.ca

A 70-year-old man was admitted to hospital because of multiple injuries from a traffic collision. On day 16 after admission, he started to complain of pain, weakness and numbness in his right leg.

A contrast-enhanced computed tomographic scan of the lumbar spine showed a displaced sacral fracture with compression of the $\mathrm{S} 1$ ventral ramus (Appendix 1, available at www. cmaj.ca/cgi/content/full/cmaj.091534/DC1). The patient's symptoms persisted despite treatment with diclofenac, chlorzoxazone, fursultiamine and betamethasone. Severe tingling pain and allodynia (pain with light touch) developed seven days later. Thirty days after admission, several painful grouped erythematous plaques with vesicles were found on his right buttock and the posterior aspect of his right leg (Figure 1). The distribution was consistent with the S1 dermatome, and a diagnosis of herpes zoster was made. The patient was prescribed valacyclovir hydrochloride, $500 \mathrm{mg}$ three times daily for five days. The cutaneous lesions healed about seven days after the treatment was started and the tingling pain resolved gradually. We discharged the patient 42 days after admission

Older age, altered cell-mediated immunity and diseases such as malignancy, chronic lung disease, renal failure and liver disease are common risk factors for herpes zoster. ${ }^{1}$ Thomas and colleagues ${ }^{2}$ reported a case-control study based in general practice in London, UK, of the determinants of zoster in adults without underlying immunosuppression. They concluded that recent trauma is associated with an adjusted 12-fold increased risk of herpes zoster at the site of injury, but not at other body sites. The increase in absolute risk was $3.9 \%$. In our patient, the major cause of reactivation of herpes zoster would seem to be

From the Divisions of Plastic Surgery (Hung, Huang), Neurosurgery (Kuo) and General Surgery (Wang), Department of Surgery, Chi-Mei Medical Center, Tainan, Taiwan

CMAJ 2010. DOI:10.1503/cmaj.091534

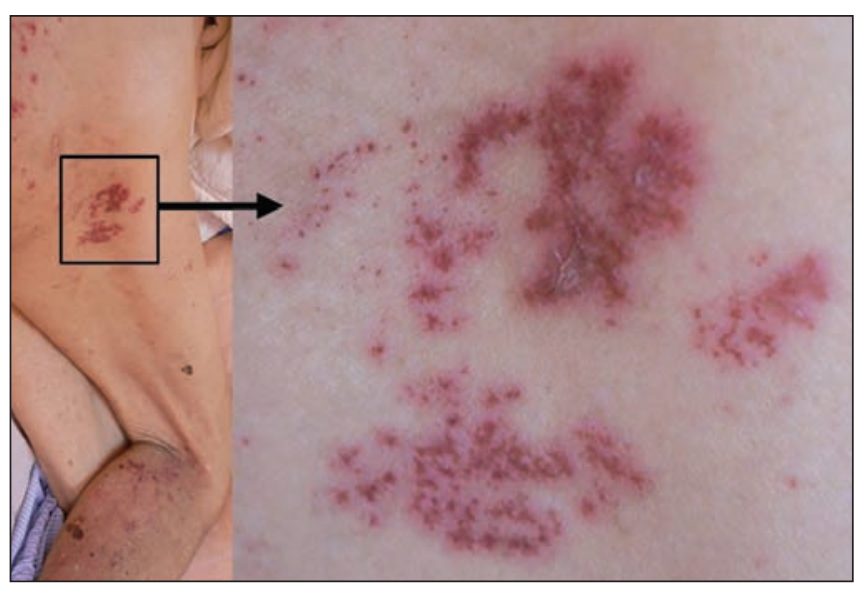

Figure 1: Painful grouped erythematous plaques with vesicles, found along the $\mathrm{S} 1$ dermatome in a 70 -year-old man, seven days after the start of sciatic symptoms.

the recent trauma. Direct stimulation of the nerve may have triggered reactivation of the virus in the dorsal root ganglion. The pain associated with herpes zoster mimicked post-traumatic sciatic pain, which made the diagnosis difficult. Although sacral segments rarely show involvement of herpes zoster, ${ }^{3}$ clincians should consider this possibility when patients are suffering from intractable pain after recent trauma.

This article has been peer reviewed.

Competing interests: None declared.

\section{REFERENCES}

1. McDonald JR, Zeringue AL, Caplan L, et al. Herpes zoster risk factors in a national cohort of veterans with rheumatoid arthritis. Clin Infect Dis 2009;48:1364-71.

2. Thomas SL, Wheeler JG, Hall AJ. Case-control study of the effect of mechanical trauma on the risk of herpes zoster. BMJ 2004;328:439-40.

3. Scheld WM, Whitley RJ, Marra CM. Infections of the central nervous system. 3rd ed. Philadelphia (PA): Lippincott, Williams \& Wilkins; 2004. p. 149. 